\title{
Identity Construction: Narrative Tension in Saul Bellow's Herzog
}

\author{
Zhengcai $\mathrm{Li}^{1}$ \& Mingying $\mathrm{Xu}^{1}$ \\ ${ }^{1}$ School of Foreign Languages, Dalian University of Technology, Dalian, China \\ Correspondence: Mingying Xu, School of Foreign Languages, Dalian University of Technology, Dalian, \\ Lingshui Road, Ganjingzi District, Dalian, China. E-mail: xumingy@dlut.edu.cn
}

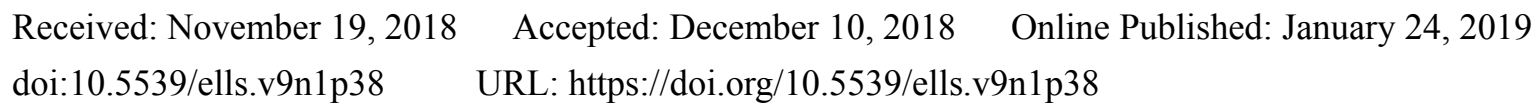

\begin{abstract}
This paper takes narrative ethics as the approach to analyze ethical dimensions of the tensions between self-narrative and other-narrative in Saul Bellow's Herzog, and indicates that self-narrative represents the protagonist's appeal of identity construction, other-narrative symbolizes external forces deconstructing his identity, and narrative reconciliation between self-narrative and other-narrative represents possibilities of his identity construction. Representational ethics shows that Herzog's self-narrative attempts to construct identity through fictionalizing ideal self at the expense of real self, then to consolidate new identities by assimilating the absolute other. However, narrational ethics suggests that other-narrative represents the absolute other's deconstruction of new identities constructed by Herzog's subjective intention, and puts all new constructed identities into suspension. Identity reconstruction can be possible only when Herzog faces the gap between real self and ideal self, confronts existence of the absolute other, responds to its ethical call, and actualizes reconciliation between self-narrative and other narrative. Besides, hermeneutic ethics indicates that the reader also has a role to play in Herzog's process of identity construction due to tensions between self-narrative and other-narrative, which bestows the reader with constantly switched ethical positions and distances from the text, thus makes the reader's responsibility towards the text an infinite movement.
\end{abstract}

Keywords: Herzog, self-narrative, other-narrative, narrative ethics, identity construction

\section{Introduction}

This paper takes Adam Newton's narrative ethics as a way to analyze the ethical dimension of narrative tensions in Saul Bellow's Herzog. The narrative structure of Herzog is alternately composed of self-narrative (first-person point-of-view) and other-narrative (third-person point-of-view). Temporarily, self-narrative appears in form of the protagonist's constant unconscious recollection of past events while other-narrative runs unrestricted through the past, present and future of the protagonist. Spatially, self-narrative appears in Herzog's stream-of-consciousness, when Herzog records his inner activities, recalls his childhood and rethinks events he complained in his unposted letters while other-narrative appears in real context, and takes the main narrative task chronically. Self-narrative is the direct representation of the flow of the protagonist's consciousness while other-narrative is speculation, description and evaluation of his inner activities. Although two narratives represent different narrative functions, they share the same perspective-Herzog's perspective. Although with the same perspective and sharing the same historical facts and ethical situations, the third narrator often intervenes and interrupts the flow of the first narrator's consciousness, expressing approval, opposition or doubtful attitude. "Any narrative form contains moral elements. ...Any narrative ultimately points to an ethical claim." (Jiang, 2014, p. 181) Therefore, the ethical dimension of narrative tensions in Herzog, especially the role those tensions play in the process of Herzog's identity construction, will be the focus of this paper.

The narrative structure of Herzog has always been Bellow scholarship's focus ever since its publication. Previous research on the ethical dimension of narrative structure can be roughly divided into two categories. One focused on Bellow's narrative techniques from the perspective of the classic and post-classical narratology theories. For example, Zhang Tingsheng, in "A Brief Analysis of Narrative Features in Herzog" (2002), took Gennet's narrative theory as approach to summarize the narrative structure of Herzog into three levels and proposed that the fragmentation and distraction of the narrative level represented the externalization of the protagonist's inner chaos. The other category concentrated on ethical interpretation of the story in the light of social ethical situations. For example, Zhu Ping's article "Saul Bellow's Positive Ethics" (2007) concluded that Herzog reflects Bellow's ethical view in the 1960s, "that is, the immortal confidence of individuals, groups and 
human beings."(Zhu, 2007, p. 27) The first category emphasizes the narrative techniques, paying too much attention to narrative levels thus ignoring the ethical dimension while the second highlights the ethical dimension of the story, especially the presentation of specific social ethics in the plot, but veils the fictional features of narrative. Therefore, the ethical dimension of Herzog's narrative structure calls for a further analysis from both narrative and ethical perspectives.

Narrative ethics will be an appropriate approach to reveal the ethical dimension of Herzog's narrative tension due to its combination of narratology and ethics. The early 1990s witnessed an intellectual "ethical turn" across disciplines such as literature, art, theory and philosophy. "This ethical turn was a direct response to the radical scepticism associated with post-structuralist or postmodernist theory which risked becoming too easily caricatured as nihilistic." (Rowe \& Horner, 2010, p. 5) In literary criticism and theory, ethical turn referred to the critical tendency that literary critics and theorists paid unprecedented attention to uncover ethical, moral, political, and cultural truths coded within a given text. The idea of literature with an ethical dimension was once "dismissed as soggy, old-fashioned, liberal-humanist thinking" (ibid), thus became unfashionable during the years of high theory in 1980s and 1990s. The principal goal and influence of ethical turn in criticism is combining literary autonomy with heteronomy, which alter the postmodernist, post-structuralist and deconstructionist slogan "nothing outside the text" into post-theorist doctrine that "there is a permanent need for a criticism that foregrounds the organizing questions of ethics, a need for an ethical vocabulary." (Parker, 1998, $p$ 7) Current theories of ethical turn mainly generates from two schools, one is American school including critics like Martha Nussbaum, Wayne booth, James Phelan, and Hills Miller; the other is European School mainly including philosophers like Emmanuel Levinas, Paul Ricoeur, etc. The former school attempts to discover ethical enlightenment from given literary works thus relies mainly on textual criticism while the latter school starts from the internal revolution within philosophy, and then leads to new perspectives on literary criticism (Chen \& Wang, 2018, p. 122).

Newton's narrative ethics established upon Emmanuel Levinas' alterity ethics and Gerard Genette's triadic narrative model. Here "ethics" comes mainly from Levinas' alterity ethics, not from normative or metaphysical ethics that Aristotle and Kant have discussed. "For Levinas, 'ethics' describes neither ontic nor deontic categories, which generalize theories of reality from subjective experience; ethics, rather, originates from the opposite direction-from the other to me, in the sensible experience of the face which he or she presents to me." (Newton, 1997, p. 12) Here "narrative" refers to narrating acts and those reciprocity generated from reading process between reader and the text, rather than the story itself. According to Genette's model, narrative could be divided into three categories, namely, (1) the story, or signified content; (2) the narrative, the signifier or narrative text; (3) narrating, the narrative act. Newton borrowed Genette's ideas, especially the third division. "Narrative ethics" doesn't mean a simple binding of them, but "narrative as ethics", which indicates that narration and narrating acts generate fictionalized ethical significance in itself. Based on Levinas' idea of "saying" and "said", "duality of Being" and "face of the other", and Mikhail Bakhtin's dialogue theory, Newton stated narrative ethics into three aspects: narrational ethics "signifies the exigent conditions and consequences of the narrative act itself"; representational ethics indicates "the costs incurred in fictionalizing oneself or others by exchanging 'person' for 'character'; and hermeneutic ethics refers to "the ethico-critical accountability which acts of reading hold their readers to" (Newton, 1997, pp. 17-18).

The main argument will unfold in three part. From representational ethics, the protagonist Herzog's attempt to construct identity through unilateral self-narrative will be revealed. From narrational ethics, the deconstructing forces of other-narrative shall be analyzed, and finally from hermeneutic ethics, reader's function in the process of Herzog's identity construction will be illustrated. This paper holds two basic ethical hypotheses before analyzing those narrative tensions: first, identification of any postmodern human being requires self identification and others' identification, thus identity construction of any individual or ethnicity is a intersubjective mission; second, identity construction is a dynamic, constantly adjusting process in postmodern world thus identification becomes an infinite movement from the self towards the other.

\section{Self-narrative as Identity Construction}

The self-narrative represents Herzog's ethical appeal to realize a certain identity since Herzog faces too many ethical crisis. His multiple identities (marriage relationship, professional identity, ethnic identity, etc) are intertwined, and conflicts with each other during the process of construction, thus leading to confusion in ethical order (Liu, 2015, p. 110). Self-narrative aims to get rid of identity crisis, which firstly requires Herzog's real cognition and expression of his culture, religion, nation, thought and ideology. Through self-narrative, Herzog sacrifices the real self to make up the ideal self, thus suspending the present identity crisis and ethical dilemma, and further obtains new ethical position by returning to Jewish ethics. As he reminisced childhood and unposted 
letters from current position, he developed two visions: one is that the "past self" thinking of ongoing things while the other is the reminiscent "present self" contemplating upon past events. (Jiang, 2014, p. 182) Regardless of differences between those two visions, they are the reflection of Herzog's inner consciousness, an objective world that has been subjectively assimilated, his empirical observation.

To actualize identity construction, Herzog attempts to realize self identification through self-representation and self-expression. Representational ethics indicates the costs incurred in fictionalizing oneself or others by exchanging "person" for "character", and "denotes the small but still momentous distance that lies between person and character, or character and caricature, the gains, losses, and risks taken up when selves represent or are represented by others." (Newton, 1997, p. 18) Representational ethics focuses on the dramatic act that one fictionalizes real persons into fictional characters and its correlative ethical responsibilities. When a real person is fictionalized into a character, either self-representing, or represented by the other, or the self representing the other, those gains and losses in representational process evidently will bring out complex ethical dimension. Gains and losses are the distances between vorbild (prototype) and Abbild (copy). According to Levinas, every Being has its duality, that is, the thing is itself at the same time it's image, and there is an irreducible distance between the self and its image. Here "a relationship between these two moments" reveals that there are forever temporal and spatial distances between the thing's true self and its the image, although the two represent each other due to their resemblance.

"Thus a person bears on his own face, alongside of its being with which he coincides, its own caricature, its own picturesqueness.... There is then a duality in this person, this thing, a duality in its being. It is what it is and it is a stranger to itself, and there is a relationship between these two moments. We will say the thing is itself and is its image. And that this relationship between the thing and its image is resemblance..... The whole of reality bears on its face its own allegory, outside of its revelation and its truth." (Levinas, 1981, pp. 6-7)

Herzog's self-narrative consists of two parts: first, his self-representation and self-expression in note-taking and selected childhood memories through which he retells individual history, suspends current crisis of identity, fictionalizes the new ethical position, and constructs individual identity, family identity and ethnic identity. Furthermore, he stands in the new ethical position, complaining and criticizing other people, current society and culture, religion and other ugly phenomena in various unposted letters and notes, to construct social identity and professional identity. Herzog recalls his childhood happiness and family life after marriage, and selects specific scenes and events to construct his identity. He recreates individual history to construct personal identity, and recreated family identity by selecting his family's enjoyable memories on Napoleon street. Moreover, he escapes marital responsibility through blaming on his former wives' infidelity. Herzog gains a new ethical position by recalling Jewish storytelling activities and revisiting his adolescent dream of becoming a Jewish rabbi. However, his childhood happiness is subjectively selected memories, a series of events idealized with integrity, continuity, and significance. Through self-representation, Herzog makes the impossible dream into possible fiction and shapes himself into the image of a Jewish rabbi. Through self-expression, he opens up the temporal and spatial and ethical distance between the real self and the ideal self, and gained a new ethical position.

Herzog stands in the new fictionalized ethical position, criticizes the ideology and social system for the bondage and alienation of people, to construct his professional identity and social identity. Herzog reinforces the ideal self-image (A Jewish rabbi in a society full of ethical chaos, spiritual paralysis, and identity crisis) through representing the infinite other in his unposted letters. He has written more than 50 letters and intends to send them to his ex-wife, brothers, lawyer, doctor, dead philosopher, politician, editor-in-chief of newspapers and so on. Herzog complains about infidelity of his second wife and betrayal of his former friend, emphasizes that he doesn't deserve such betrayal, thus shaping himself into a morally victim in his letters to the psychiatrist, lawyers In the letter to his millionaire brother, Herzog expresses his critique of rich bourgeoisie, arguing that his brother is a complete utilitarian and hedonist, thus making himself a noble person who regards money as nothing. Herzog's critique of society and others has adopted double standards. On the one hand, he demands others with Jewish ethics, while on the other hand he never makes similar demands and criticisms upon himself. So these unposted letters are just a virtual space in which he complains, criticizes others, and consolidates the results of his self-narrative. Herzog, in a new ethical position, assimilate the other through self-narrative, temporarily suspends many ethical crisis in reality and ignores the ethical call of the other.

Herzog's self-narrative has inherent ethical paradoxes, leading his identity construction in vain. According to Levinas, every Being has duality, and there is an irreducible distance between the self and its image. Therefore, self-representation and self-expression can't be completely actualized since the self is not a continuous, complete, meaningful whole, but a broken, divergent, purposeless thing. The paradoxes are between the purpose and means of Herzog's self-narrative intention. Purpose of self-narrative is to construct identity in real life, while means to 
achieve that purpose are constructing individual history and recreating an ideal self-image through subjectively selected memories of childhood happiness, and consolidating fictionalized ethical position in virtual letters by criticizing the various phenomena of the current society and culture.

\section{Other-narrative as Identity Deconstruction}

The other-narrative's suspension, denial, and critique upon Herzog's self-narrative form the external deconstruction of Herzog's newly constructed identities. Identity construction must be "based on the recognition of a common origin or shared feature, that is, sharing certain characteristics with another group, community, or organization," (Chen, 2016, p. 25), which also requires other's positive participation and recognition. "Identity is never the same or unified, but pluralistic and fragmented; identity is never in a stable and fixed state, but in a historical process of constant change." (Chen, 2016, p. 25) Therefore identity construction is an infinite process involving intersubjective relationship between the self and the other. History, society, and others put forward ethical requirements upon the self, and pull the self into dialogue. To achieve identity construction, Herzog must understand the differences between the self and the other, his culture and foreign culture, respond to ethical calls from the other, and build a shared identical, ethical and cultural foundation.

Narrational ethics signifies the exigent conditions and consequences of the narrative act itself, which refers to "what narratologists call 'narrative situation' or 'narrative act,' ...the dialogic system of exchanges at work among tellers, listeners, and witnesses, and the intersubjective responsibilities and claims which follow from acts of storytelling" (Newton, 1997, p. 18). Narrational ethics focuses on ethical features of narrating acts, various intersubjective responsibilities generated from the whole narrating chain, from the author, to the narrator, then to the narrated, next to the reader. Newton's ideas base upon Levinas' distinction between "saying" and "said". "Said" is ontological, and the logic rationality in the traditional ontological philosophy, such as representation, summarization, and induction, all point to the known entity; on the contrary, "saying" is ethical, its transcendence over "said" has practicality and its key feature is a humility gesture toward the other. "The "said" is static and solidifies the language while the 'saying' is dynamic and tries to escape from the imprisonment of language; the 'said' is the field of the self by assimilating the other to self-other existence while the 'saying' shows the way to the other by pointing to the transcendental other that different from the existence." (Chen \& Wang, 2018, p. 124) Levinas emphasizes the superiority of "saying" over "said". Narrative ethics is similar to Levinas's concept "saying" because storytelling is a narrative, not a complete copy of facts, a presentation or exposure of the self. (Wu, 2014, p. 127) "Saying" emphasizes endogenous relationship between narrative discourse and ethics, and pays attention to dialogue between the narrator and the other, thus becomes the essential way for the self to face the other. "Said" defines and maintains the field of self, closing the path of self toward others. Herzog's approach to construct identity by self-narrative represents "said", which assimilate the true self and the other into a fictional self-existence, solidifying the subjective-objective relationship between the self and the other. The deconstruction of identity by other narratives symbolizes "saying", breaking the assimilation of self-narrative, putting Herzog into dialogue with the other, and making identity construction a dynamic intersubjective process. The deconstruction of identity reflects the dynamic ethical relationship between narrators, narrator and the narrated. From the perspective of narrational ethics, deconstruction of identity in other-narrative has at least three different levels.

Firstly, the other-narrative deconstructs Herzog's individual identity. The other narrative represents the division of Herzog's external image and internal cognition. Herzog's external image is a liberal, an intellectual, a theorist, a madman, an idiot, a fool while his inner self-recognition is "a thoughtful person". Herzog's ethical norms and ethical behaviors are seriously inconsistent. He uses Jewish doctrine to demand his wife's loyalty to marriage, his friends' loyalty to friendship, but never obeys those doctrines himself. Obviously, Herzog uses double ethical standards to deal with his inner self-cognition and external behaviors. Therefore, deconstruction of other-narrative can be understood as the sharp opposition between ethical demands of Herzog's ideal self and real self. First-and third-narrators symbolize Herzog's schizoid personality and identity crisis since Herzog wants to be integrated into American society and puritan culture, while he wants to keep his own Jewish identity and culture as therapeutic methods to those social and cultural problems he complains.

Secondly, other-narrative deconstructs Herzog's family identity and ethnic identity. The suspension of identity construction from the other-narrative symbolizes the conflict between the ethical appeal of two generations of Jewish immigrants. The elder generation chooses to adhere to Jewish culture and resist erosion of the dominant culture, such as Herzog's parents. The new generation chooses to actively integrate into dominant culture, and even give up their Jewish identity, such as Herzog's siblings and his second wife. The failure of Herzog's father to maintain and worship Jewish culture leads Herzog's siblings to abandon their Jewish identity and integrate into puritan culture for material success. However, Herzog, as an intellectual who wanted to be Jewish rabbi, 
hesitates his own integration, and endeavors to keep a balance between those two discrepant cultures. Herzog swings between two ethnic identities of Americans and Jewish descendants, trying to construct identity within both cultures. On the one hand, tensions between Herzog and his father shows that traditional Jews does not recognize Herzog's yearning for American society. On the other hand, Herzog's unhappy marriage and his siblings' misunderstandings indicate that new Jewish generation also does not recognize Herzog's effort. Herzog is sandwiched between two cultures, two ethnic identities, and two types of ethical appeals. His family identity and ethnic identity constructed through self-narrative become broken bubbles.

Moreover, other-narrative deconstructs Herzog's social identity and professional identity. The two narrators represent Jewish appeal to rewriting collective and individual history and the oppression upon that appeal from mainstream discourse. The division of narrators dramatize Jewish intellectuals' endeavors to write their own history and narrate their story rather than be written and represented by dominant values at that time. Conflicts between Jewish culture and dominant culture, Jewish doctrines and puritan doctrines, Jewish people and white people were embellished by those orthodox historians who represented dominant values after World War II. Therefore those anti-Semitism and correlative historical events of oppression were neglected on purpose. Thus Jewish intellectuals made their efforts to write their memory and history. Besides, those alternate history Jewish intellectuals rewrite includes not only historical events occurred, but also those events might have happen under the similar condition (Li \& Zhang et al., 2018, p. 850). By recalling childhood, Herzog recollects Jewish immigrants' encounters, retells individual history and collective memory, rewrites historical facts, and dramatizes events that are likely to occur. Therefore, other-narrative represents the suppression of the mainstream discourse upon Herzog's effort to rewriting history and recreating identity. Herzog's social and professional identity constructed within self-narrative are difficult to actualize.

Other-narrative deconstructs Herzog's individual, family, ethnic, professional, and social identity constructed in self-narrative. Self-narrative fictionalizes the ideal self by sacrificing the real self, assimilating the absolute other to achieve static identity. However, whether Herzog's true self or the absolute other, has escaped his subjective assimilating process, deconstructing the solidified and static identity in the form of other-narrative. To achieve identity, Herzog must realize that identity construction requires both self-identification and other identification. Self-identification requires proper treatment of the distance between real self and fictionalized self. Other identification requires the self to realize the freedom of the absolute other, respond to its ethical call, and construct dynamic identity in the dialogue with the other.

\section{Narrative Reconciliation and Identity Reconstruction}

Narrative ethics emphasizes that narrative activity is an intersubjective process. Characters present ethical requirements to others by presenting and exposing themselves, and pulling others into dialogue. Newton's concept is similar to Levinas's concept "Face of the Other". Face is the way of exposure for the other, and functions as an intermediary, only through which can the self encounter the absolute other, and the absolute other unfolds its exteriotiry and infiniteness. "The way in which the other presents himself, exceeding the idea of the other in me, we here name face." (Levinas, 1969, p. 50) When the self encounters the other, face of the other, the appearance and revelation of the other transcends one's possession. On one hand, "the face resists possession, resists my powers," and "the resistance of the other does not do violence to me, does not act negatively; it has a positive structure: ethical", on the other hand, "the face speaks to me and thereby invites me to a relation incommensurate with a power exercised, be it enjoyment or knowledge" (Levinas, 1969, pp. 197-198).

To achieve identity construction, Herzog must face his own individual history, represent his real self, and reach a reconciliation with the other in dialogue. Herzog finally realizes that his behavior implied an obstacle in his life, which he has been trying to overcome from the beginning and through out his life because he thinks he has to rule it out, and will definitely get results. (Bellow, 2002, p. 300) On one hand, "obstacle" refers to the gap between Herzog's real self and fictionalized self. Only by facing his individual history and ethical crisis, can he rule out this obstacle and bridge the gap, then achieve self identification. On the other hand, "obstacle" refers to the irreducible ethical distance between the self and the other. Herzog can achieve identification only by realizing the independence of the other and responding to its ethical call, rather than assimilating the other. As Bothwell indicated, only when Herzog stops subjectively judging others, can he reconnect with others and end his self-exile. (Bothwell, 1980, p. 136) At the end of the novel, Herzog realized the reconciliation between self-narrative and other-narrative, thus unfold multiple possibilities of identity construction. In the country house, the true concern from his brothers and girlfriend, and Herzog's love for his children proves that his efforts to construct identity have undergone essential changes. He no longer pursues the assimilation of the other by self-narrative, no longer immerses himself in reminiscing the past, or writing letters complaining about social injustice, but focuses on real life, caring for people and events around him. 
In addition, the reader is also involved in the process of Herzog's identity construction. The alternation of the other-narrative and self-narrative makes the ethical distance between the reader and the text constantly changing, thus summons the reader to engage in dialogue with the latter and undertake corresponding ethical responsibilities. In the reading process, the text functions as the absolute other inviting the reader into an ethical relationship, thus reader's activities have ethical responsibilities. "The responsibility is twofold. In part it means learning the paradoxical lesson that getting someone else's story is also a way of losing the person as real, as what he is; it is a way of appropriating or allegorizing that endangers both intimacy and ethical duty. At the same time, however, one's responsibility consists of responding to just this paradox." (Newton, 1997, p. 19) Besides that, "Reading story takes the form of a constant drawing-nearer; and yet, paradoxically, the closer we approach the text, the farther away from it we get, and the more exorbitant our responsibility toward it consequently becomes-an infinite movement."(Newton, 1997, p. 20) Newton argues that "One faces a text as one might face a person, having to confront the claims raised by that very immediacy, an immediacy of contact, not of meaning." (1997, p. 11) The relationship between the reader and the text calls for intersubjective responsibilities as that Levinas holds: the self has infinite responsibility towards face of the other. In Levinas' view, art works are also the ethical other. Experiencing art works is to establish a fair relationship with the other. The fundamental prescriptiveness of art works is that the understanding of art should not be an absolute domination. If the other is completely assimilated with the self, it is actually "murder." Thus the reader's undertakes infinite ethical responsibilities in the reading process.

The control of ethical distances between the reader and the text is actualized by various matches between narrative perspectives and narrative voices, namely, matches between who is seeing and who is speaking. In the novel Herzog, the focalization seems fix upon one person, the character Herzog. However, careful inspection would discover that the focalization is flexible since there are at least four "Herzog"s in that text: the reflective and deliberating narrator Herzog; the fictionalized childhood Herzog presented as a character by the first-person narrator; the idealized Herzog as Jewish rabbi in his letters; and the last Herzog who wanders around. On the surface there are only two narrators, the narrator Herzog and the third-person narrator. However the third-person narrator can be further divided into at least four groups: the other Herzog (Herzog's schizoid personality) as we discussed in part one; Herzog's Jewish fellow who have integrated into society; those White people that Herzog criticized in his letters; the invisible author. So there are totally four narrative perspectives and five narrative voices, which could form over twenty matches. Behind each single match lies a certain ethical distance between the reader and the text, leading to various ethical responsibilities. For example, the reader's feelings about Herzog caused by the match between the perspective from idealized Herzog in letters and the first-person narrator, might be different from those feelings caused by the match between the perspective from child Herzog in memories and the third-person narrator functions as the invisible author. Those matches between narrative perspectives and narrative voices might again confirm that any ethical identification could not come true without participation of the other. Furthermore, the switch among different matches will finally pass on the narrative authority to the reader: from the character Herzog, to the narrator Herzog, then to the third-person narrator, to the invisible author, and finally to the reader. "The narrator gives the story's progressive transfer of authority to the reader as his or her problem, so that answerability resides-taken up or refused-outside the story's representational and aesthetic limits." (Newton, 1997, p. 21) The final scene of the novel leaves hundreds of possibilities opens to us. The reader gets the final judgment but the reader has to take the need of the absolute other (the text) into consideration.

\section{Conclusion}

This paper analyzed the ethical dimension of narrative tensions in Bellow's Herzog by the approach of narrative ethics. It has been found that self-narrative represents the protagonist's appeal of identity construction, other-narrative symbolizes external forces deconstructing his identity, and narrative reconciliation between self-narrative and other-narrative represents possible realization of his identity construction. Representational ethics shows that Herzog's self-narrative attempts to construct identity through fictionalizing ideal self at the expense of real self, then to consolidate new identity by assimilating the infinite other. However, narrational ethics suggests that other-narrative represents the infinite other's deconstruction of new identities constructed by Herzog's subjective intention, and puts all new constructed identities into suspension. The identity reconstruction can be possible only when Herzog faces the gap between real self and ideal self, confronts existence of the infinite other and responds to its ethical call, and actualizes reconciliation between self-narrative and other narrative. Besides, hermeneutic ethics indicates that the reader also has a role to play in Herzog's process of identity construction due to tensions between self-narrative and other-narrative, which bestows the reader with constantly switched ethical positions and distances from the text, thus makes the reader's responsibility towards 
the text an infinite movement.

\section{Acknowledgments}

The research is supported by "the Fundamental Research Funds for the Central Universities", Project No. DUT17RW125 and "Liaoning Social Science Planning Fund" funded by Liaoning Planning Provincial Office of Social Science, Project No. L18BWW006.

\section{References}

Bellow, S. (2002). Herzog. Song Zhaolin trans. Shijiazhuang: Heibei Education Press.

Bothwell, E. K. (1980). Alienation in the Jewish American Novel of the Sixties. Riopiedras: Univerdidad de Puerto Rico.

Chen, B., \& Wang, S. R. (2018). Towards an Alterity Ethical Literary Criticism in Literary Ethical Turn. Nanjing Journal of Social Sciences, 2, 120-126.

Chen, Y. G. (2016). Identification and the Politics of Literature. Journal of Tsinghua University (Philosophy and Social Sciences), 31(06), 22-31.

Jiang, S. Y. (2014). Ethical Interpretation of Narrative Perspective in Novels. Theoretical Studies in Literature and Art, 5, 180-188.

Levinas, E. (1969). Totality and Infinity: An Essay on Exteriotiry. A. Lingis (trans.). Pennsylvania: Duquesne University Press.

Levinas, E. (1981). Reality and Its Shadow. In A. Lingis (Ed.), Collected Philosophical Papers. Dordrecht: Martinus Nijhoff.

Li, W. P., Zhang, L., et al. (2018). A History of American Literary Thought. Shanghai: Shanghai Foreign Language Education Press.

Liu, X. Y. (2015). Ethical Identity and Ethical Choice in Herzog. Foreign Literature Studies, 6, 109-115.

Newton, A. (1997). Narrative Ethics. Massachusetts: Harvard University Press.

Parker, D. (1998). Introduction: the turn to ethics in the 1990s. In J. Adamson, R. Freadman \& D. Parker (Eds.), Renegotiating Ethics in Literature, Philosophy and Theory (pp. 1-20). London: Cambridge University Press. https://doi.org/10.1017/CBO9780511586200.001

Rowe, A., \& Horner, A. (2010). Introduction: Art, Morals and The Discovery of Reality. In A. Rowe \& A. Horner (Eds.), Iris Murdoch and Morality (pp. 1-14). London: Palgrave Macmillan. https://doi.org/10.1057/9780230277229_1

Wu, M. G. (2014). Narrative Ethics in Vision of the Ethical Turn. Journal of Henan University (Social Science), 54(1), 101-107.

Zhu, P. (2007). Saul Bellow's Positive Ethics. Foreign Literature Review, 2, 27-35.

\section{Copyrights}

Copyright for this article is retained by the author(s), with first publication rights granted to the journal.

This is an open-access article distributed under the terms and conditions of the Creative Commons Attribution license (http://creativecommons.org/licenses/by/4.0/). 